\title{
C-A/AP/518
}

June 2014

\section{p-Au Ramp Test}

\section{C.Montag, M. Blaskiewicz, V. Schoefer, I. Blackler, A. Marusic, T. Shrey}

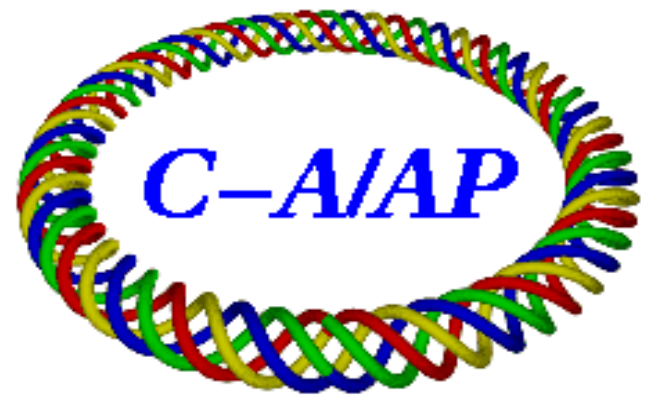

\section{Collider-Accelerator Department Brookhaven National Laboratory Upton, NY 11973}

Notice: This document has been authorized by employees of Brookhaven Science Associates, LLC under Contract No. DE-AC02-98CH10886 with the U.S. Department of Energy. The United States Government retains a nonexclusive, paid-up, irrevocable, world-wide license to publish or reproduce the published form of this document, or allow others to do so, for United States Government purposes. 


\title{
p-Au Ramp Test
}

\author{
C. Montag, M. Blaskiewicz, V. Schoefer, I. Blackler, \\ A. Marusic, T. Shrey
}

June 10, 2014

\section{Introduction}

During FY2015 RHIC will be providing proton-gold collisions for the first time. The large difference in $Z / A$ of these species results in challenging conditions at injection. Two injection scenarios are under investigation:

- Injection at equal $B \rho$, which results in different revolution frequencies of the two beams;

- Injection at equal revolution frequencies, which requires different rigidities $B \rho$ of protons and gold.

Injection at unequal revolution frequencies was attempted in RHIC during the deuteron-gold run in FY2003. The resulting modulated beam-beam interaction during injection and ramp caused significant beam loss that severely limited the machine performance [1].

To overcome these limitations, injection at equal revolution frequencies is preferred. However, the injection energy for gold ions is limited by the maximum AGS extraction energy and the pulsed power injection and extraction elements to $\gamma_{\mathrm{Au}}=10.5$. On the other hand, it is desirable to inject the polarized proton beam above the RHIC transition energy of $\gamma_{t}=23$. Keeping the revolution frequencies of the two beams identical can therefore only be accomplished by injecting the $\mathrm{Au}$ ions at $\gamma_{\mathrm{Au}}=10.5$, and ramping them to the proton injection energy of $\gamma_{p}=25.3$. After proton injection both beams are then ramped to their desired storage energy, keeping the revolution frequencies of the two rings locked to each other.

This latter scenario requires ramping the Au beam to an energy just above the RHIC transition energy. This may potentially lead to longitudinal multibunch instabilites due to the short bunch length in the vicinity of transition. On June 4, 2014, the au ramp was therefore tested during APEX.

\section{Experimental Results}

During the experiment, six $\mathrm{Au}$ bunches with bunch intensities of $1.6 \cdot 10^{9}$ ions/bunch were injected into each RHIC ring at $\gamma_{\mathrm{Au}}=10.5$, and accelerated to 


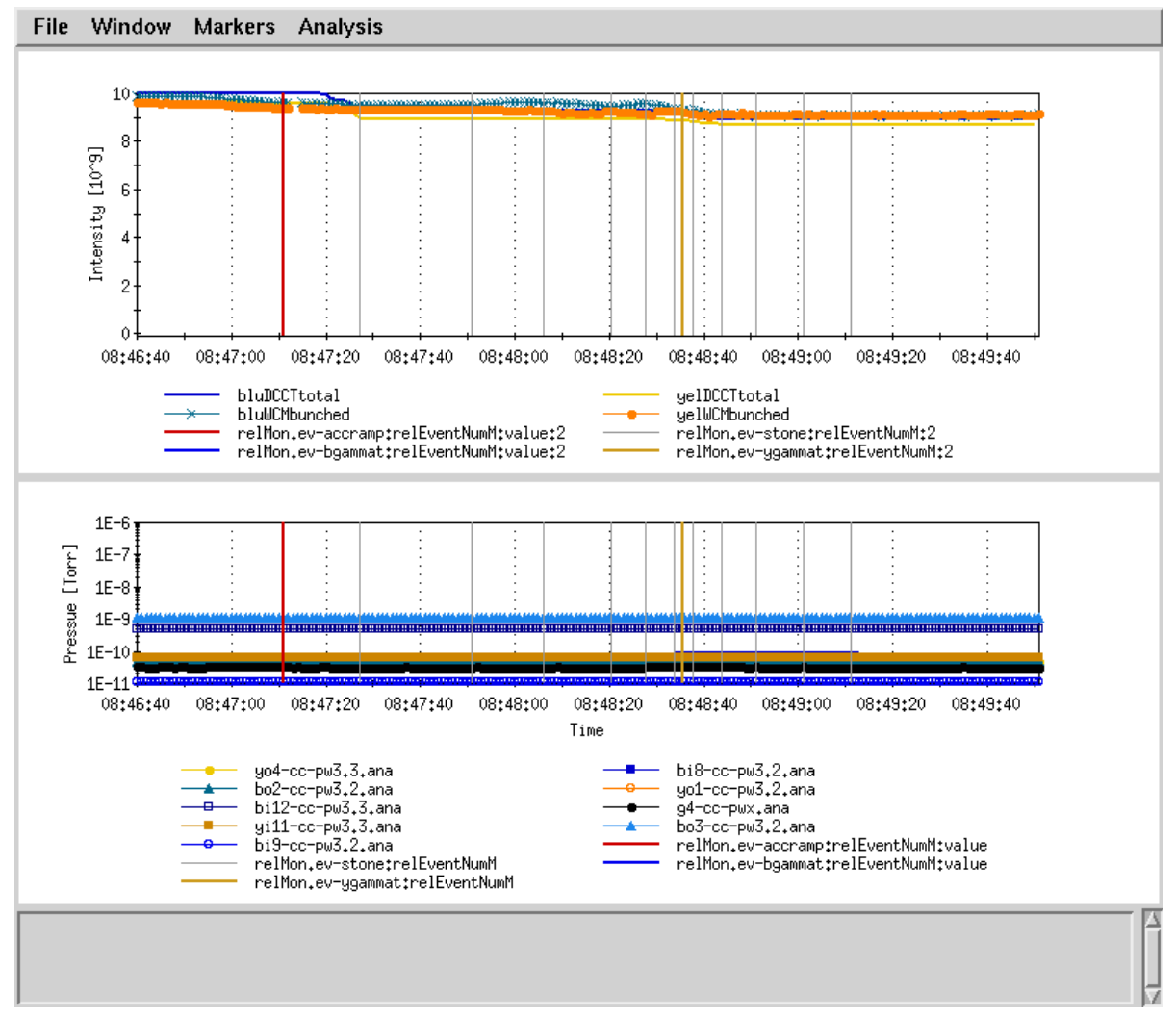

Figure 1: Ramp with 6x6 through transition

the proton injection energy of $\gamma_{\mathrm{p}}=25.3$. As Figure 1 shows, both beams were ramped with over 90 percent efficiency.

On that proton injection porch, both the horizontal emittance and the bunch length grew by roughly 15 percent in $15 \mathrm{~min}$ due to intrabeam scattering, see Figure 2. The vertical emittance remained constant, as one would expect in a well decoupled machine.

The subsequent ramp to $100 \mathrm{GeV} / \mathrm{n}$ did not show any significant beam loss as well until the beam was lost late in the ramp due to an unrelated technical issue, Figure 3.

After the successful test with 6 bunches per ring, 111 bunches with $1.6 \cdot 10^{9}$ $\mathrm{Au}$ ions/bunch were injected in each ring and accelerated through transition, Figure 4. Again the ramp efficiency was comparable to regular RHIC ramps, and no signs of instability were detected. 


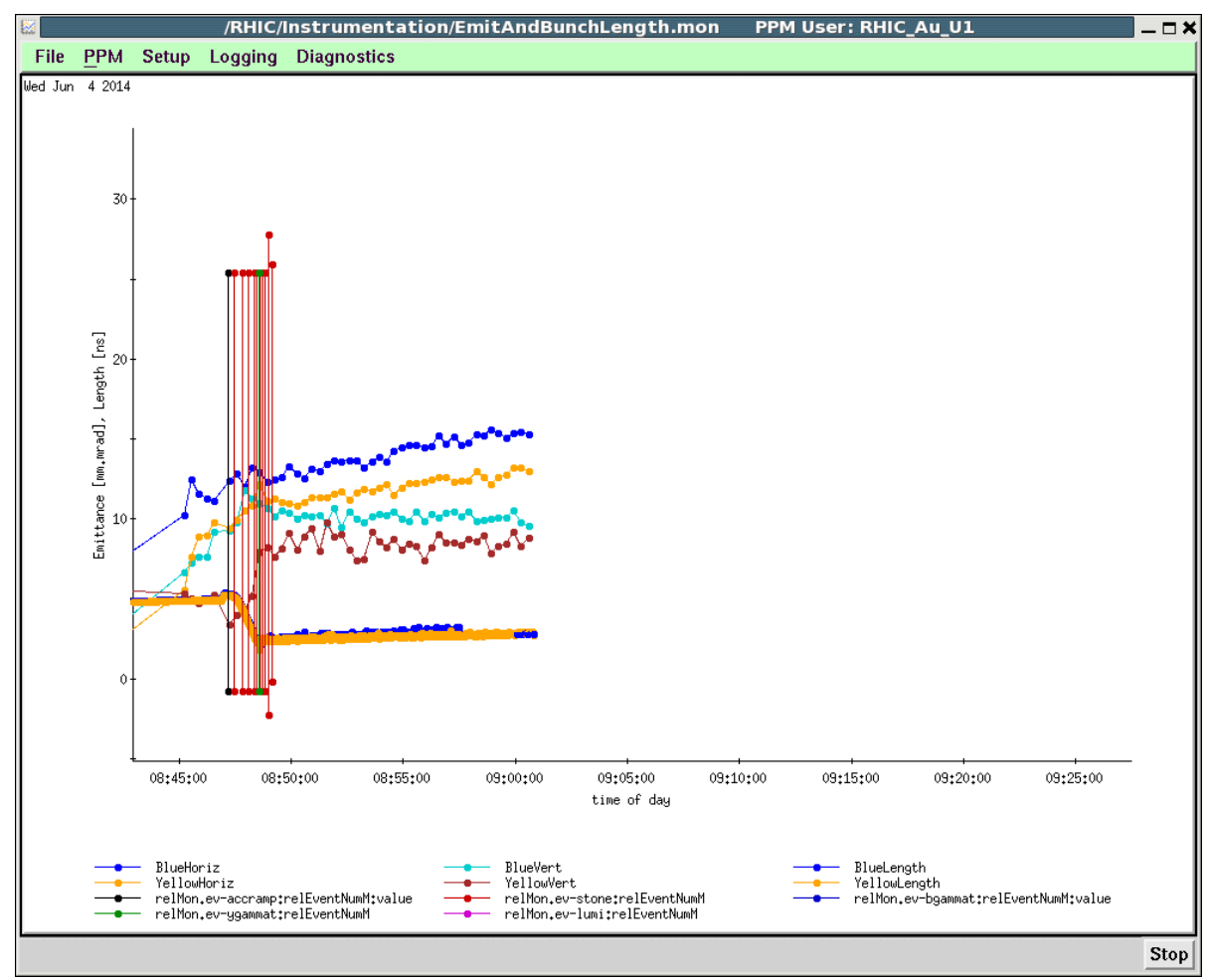

Figure 2: Emittances and bunch length on the proton injection porch 


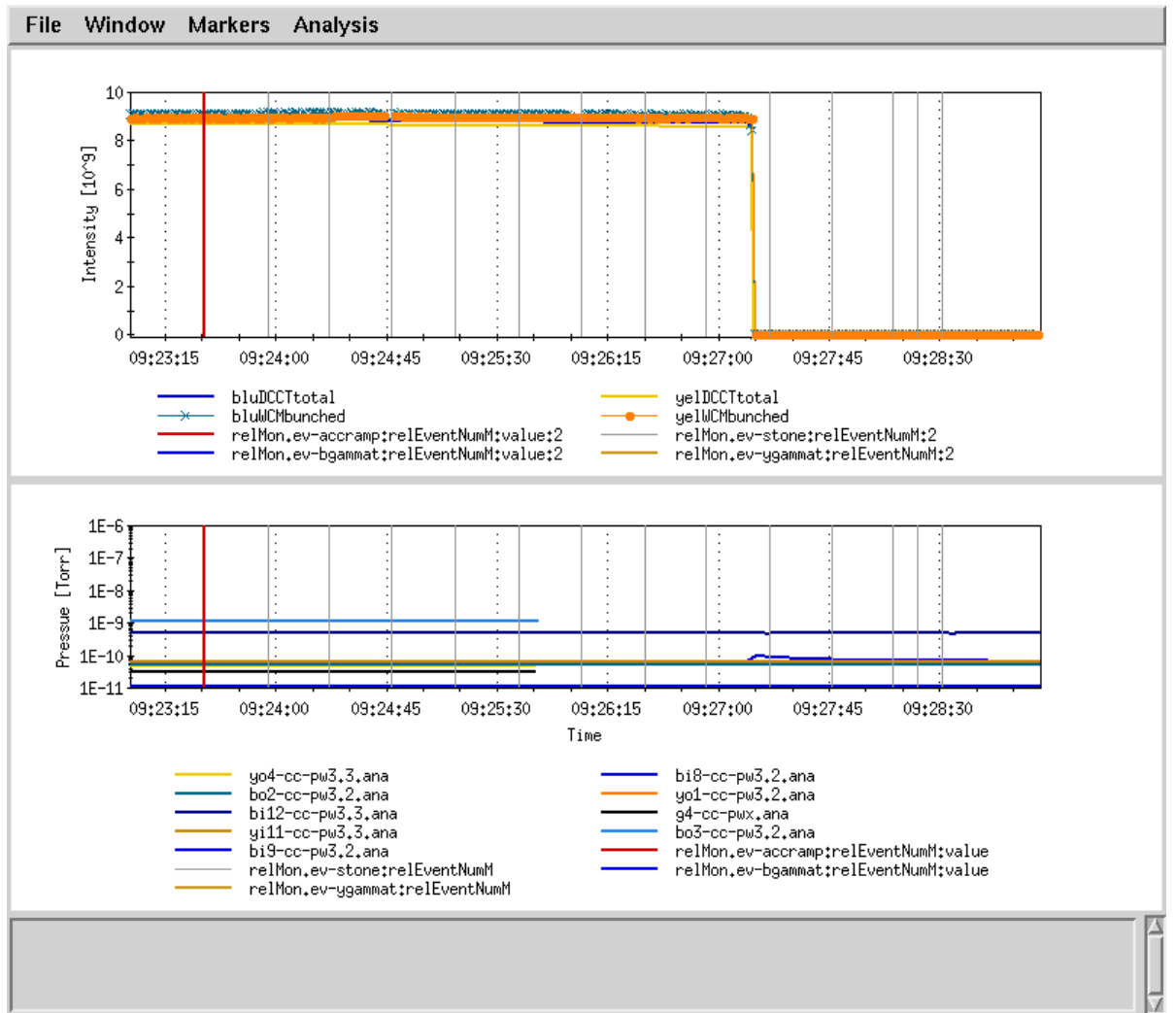

Figure 3: Ramp with $6 \times 6$ from transition to flattop 


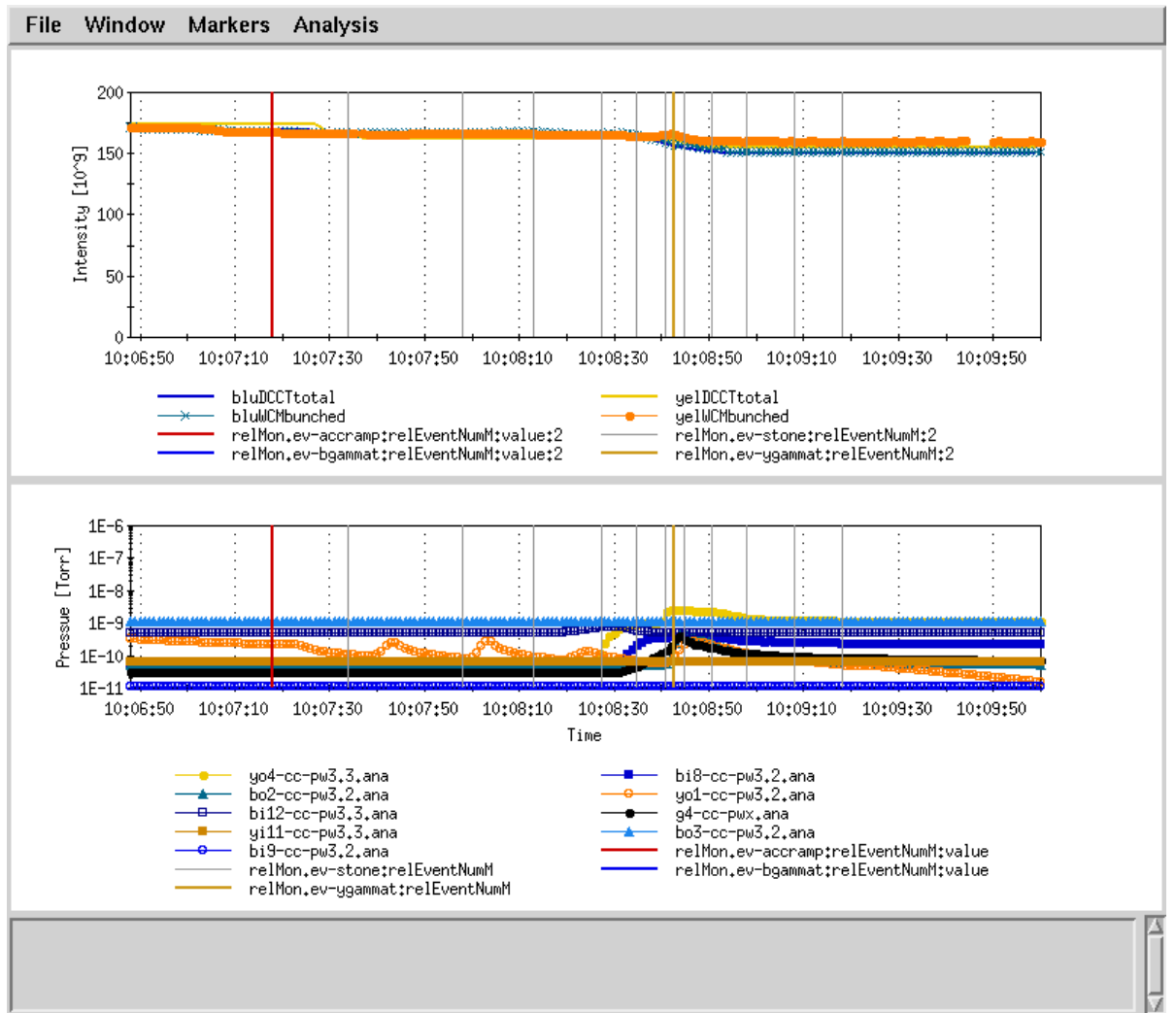

Figure 4: Ramp with $111 \times 111$ through transition 


\section{Conclusion}

During the APEX test Au beams with $1.6 \cdot 10^{9}$ ions/bunch were successfully ramped as required for $\mathrm{p}-\mathrm{Au}$ operations at equal frequencies. The observed emittance growth on proton injection porch at $\gamma=25.3$ is minor, and no signs of an instability due to vicinity of transition were detected. Acceleration from $\gamma=25.3$ to store worked flawlessly; the beam loss later in the ramp was caused by an unrelated technical problem. This ramping scenario with equal frequencies is therefore the preferred scheme for p-Au operations in FY2015.

\section{References}

[1] T. Satogata et al., AIP Conf. Proc. 693 (2004) 252-255 